\title{
VARIATIONS IN THE DIMENSIONS OF SUB AXIAL VERTEBRAE AND
} ITS CLINICAL SIGNIFICANCE

\section{V.Ananthi ${ }^{* 1}$, S.Umarani ${ }^{2}$, V.Muniappan ${ }^{3}$.}

${ }^{* 1}$ Tutor, Department of Anatomy, Rajah Muthiah Medical College, Chidambaram, Tamil Nadu, India.

${ }^{2}$ Assistant Professor, Department of Anatomy, Rajah Muthiah Medical College, Chidambaram, Tamil Nadu, India.

${ }^{3}$ Professor and Head, Department of Anatomy, Rajah Muthiah Medical College, Chidambaram, Tamil Nadu, India.

\section{ABSTRACT}

Introduction: cervical vertebrae are the upper most vertebrae in vertebral column. They are more prone to damage during road traffic accidents. Their dimensions are important for various spinal surgical procedures to access the spinal cord for decompression procedures.

Aim and Objective: Variations in the dimensions of sub axial vertebrae is of very important for spinal surgical procedures like Transpedicular screwing, Laminectomy, Foraminectomy, Transcorporeal Micro decompression surgery. The present study was done in the C3-C7 vertebrae of south Indians to know the Mean values of various dimensions of sub axial vertebrae.

Materials and Methods: The present study was done in 60 sub axial vertebrae, which were done in Rajah Muthiah Medical College, Chidambaram. Dimensions of Body (Antero posterior Length, Transverse Length \& Height), Pedicle (Height, Length \& Width), Lamina (Length, width \& Height), Foramen Transversorium (Antero posterior Diameter, Transverse Diameter), Spinous process (Length) were studied.

Main outcome measure: Variations in the dimensions of body, pedicle, lamina, Spinous process, Foramen transversorium were observed.

Result: The Mean values of dimensions of vertebral body, lamina, pedicle, Foramen Transversorium \& Spinous process were measured. Dimensions of body was maximum at C6 level. Length of pedicle was maximum at C3, Minimum at C6. Height \& width of pedicle gradually increase from C3 to C7. Height of Lamina was maximum at C6, Length \& width of Laminae was gradually increases from C3 to C7.

Conclusion: This study will provide the knowledge about dimensions of sub axial vertebrae in South Indian population. This will be helpful for spinal Surgeries \& Radiological Interpretations.

KEY WORDS: Sub axial cervical vertebrae, Transpedicular fixation, Laminectomy, Foramenectomy.

Address for Correspondence: Dr.V.Ananthi, Tutor, Department of Anatomy, Rajah Muthiah Medical College, Chidambaram, Tamil Nadu, India. E-Mail: ananthisricharan@gmail.com

\section{Access this Article online}

\section{Quick Response code}

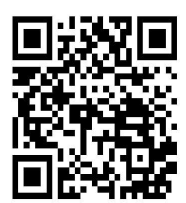

DOI: $10.16965 /$ ijar.2017.461
Web site: International Journal of Anatomy and Research

ISSN 2321-4287

www.ijmhr.org/ijar.htm
Received: 25 Jun 2017

Peer Review: 26 Sep 2017

Revised: None
Accepted: 08 Nov 2017

Published (O): 01 Dec 2017

Published (P): 01 Dec 2017

\section{INTRODUCTION}

The cervical vertebrae are seven in number; They developed from sclerotome around notochord.
The cervical part of vertebral column presents a curvature which is formed around 3-4 months after birth. When the infant learns to erect its 
head. Normally there are 2 primary curvatures - thoracic and sacral curvatures. The other two secondary curvatures are cervical \& lumbar; cervical curvature is formed during 3-4 months after birth; Lumbar curvature formed when the baby learns to walk.

The cervical vertebrae, the smallest of the movable vertebrae are typified by a foramen in each transverse process. Among 7 vertebrae 1, 2, 7 are having special features, so they are called as atypical vertebrae other 4 vertebrae are typical vertebrae they have common features.

The typical cervical vertebrae has a body, pedicles, lamina, spinous process, Transverse process, superior and Inferior articular processes, and foramens in the transverse process. The mature transverse process is formed by fusion of costal element with body and true transverse process [1]. The cervical curvature has its important functions. Due to fracture and disorders of cervical Spine serious damages may occur, approximately 5 to $10 \%$ of unconscious patients who come to emergency unit as a result of motor vehicle accidents or fall have a major injury to cervical spine. More Cervical spine fractures occur at 2 levels one at C1 - C2 level, other at C6-C7 Level.

\section{Cervical Spine can be viewed as $\mathbf{3}$ columns:}

Anterior: Includes anterior longitudinal ligament, Anterior $2 / 3$ of body. Middle: Includes posterior $1 / 3$ of body $\&$ Posterior longitudinal ligament, IV discs. Posterior: Contains all bony elements pedicles, lamina, transverse process, spinous process [2].

If one column is disrupted; other columns may provide sufficient stability to prevent spinal cord Injury. If 2 columns are disrupted, the spine may move as 2 separate units, increases the possibilities of spinal cord injury. Most of the injuries causes unstable spinal cord. In treatment of spinal cord instability and decompression of neurological structures, many procedures are followed like Kyphoplasty, Vertebroplasty, Vertebral column instrumentation and placement of Transpedicular Screws; The size and dimensions of various parts of vertebrae may vary one from another. It also varies among various population. The morphometric dimensions like vertebral body's Antero posterior(AP) length,
Transverse(T) Length, Height, Foramen Transversorium's Length, breadth, width, Lamina length, width, Pedicle's length , width, length of spinous process of our study will be useful to spinal surgeons for their spinal fixation procedures. Many people spent their precious time in studying the dimensions of sub axial vertebrae. Our present study will provide knowledge about dimensions of cervical vertebrae in south Indian population.

\section{MATERIALS AND METHODS}

Sixty dry human sub axial vertebrae of unknown sex and age has been collected from Rajah Muthiah Medical College \& Hospital, Annamalai Nagar, Chidambaram. Normal intact vertebras were only taken for the study. Damaged and fractured vertebras have been excluded. The dimensions of body, lamina, pedicle, spinous process, Foramen Transversorium were measured using spreading and gliding caliper. The measurements we observed were following:

Body:

AP length: Distance between anterior and posterior surface of body at midline (fig. 1).

Transverse length: Distance between two lateral surfaces of the vertebral body (fig. 1).

Height: Distance between superior \& inferior borders of vertebral body at midline (fig. 3 ).

Pedicle:

Length: Distance between the anterior limit of superior articular facet and posterior limit of the vertebral body(fig 2)

Width: Distance between the medial \& lateral borders(fig 2).

Height: Distance between superior \& inferior border of pedicle (fig 2)

Lamina:

Length: Distance between the spinous process and lateral border of superior articular process(fig 2)

Height: Distance between superior \& inferior borders of lamina (fig 2)

Width: Distance between medial \& lateral borders. (fig 2)

Spinous process: Length: Distance from superior border to tip of the spinous process.(fig 2) 


\section{Foramen Transversorium:}

Anterio posterior and transverse diameter of Right \& Left side has been measured(fig 1)

Statistical analysis: Statistical analysis was done for each measurement. Mean and standard deviations were performed using SPSS ver.20.

\section{RESULTS}

Sixty sub axial vertebrae were studied. The differences for all the evaluated parameters between right and left side were found insignificant except Foramen transversorium.

Bodies: Transverse length of the body was maximum at $\mathrm{C} 6$ and minimum at $\mathrm{C} 3$; AP length of body was maximum at $\mathrm{C} 6$ minimum at $\mathrm{C} 3$. But Height of body gradually increases from $\mathrm{C} 3$ to C7 (Table 1).

Pedicles: Pedicle length was maximum at C3, minimum at C6; the pedicle height and width gradually increases from C3 to C7.(Table 2)

Laminae: Laminae length gradually decreases from C3 to C7; but Lamina height was minimum at C3 and Maximum at C6; width of lamina was minimum at $\mathrm{C5}$, maximum at $\mathrm{C3}$.(Table 3)

Spinous Process: Length of spinous process was maximum at C3, Minimum at C7.(Table 4)

Fig.1: Dimensions of Body

,Pedicle \&

Foramen

Transversorium.

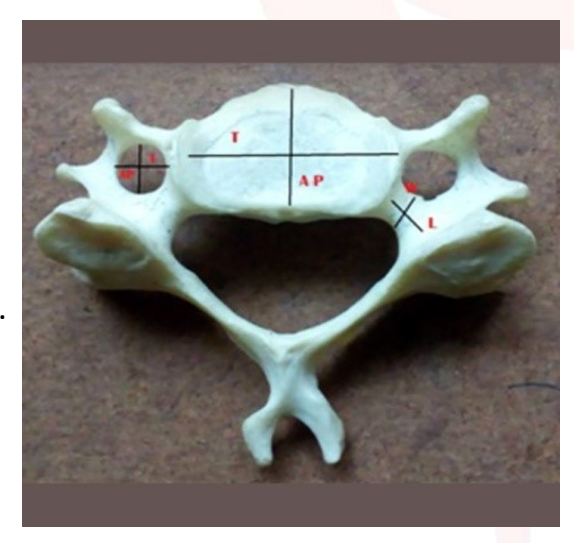

Fig. 2: Dimensions of Lamina

\& Spinous

Process.

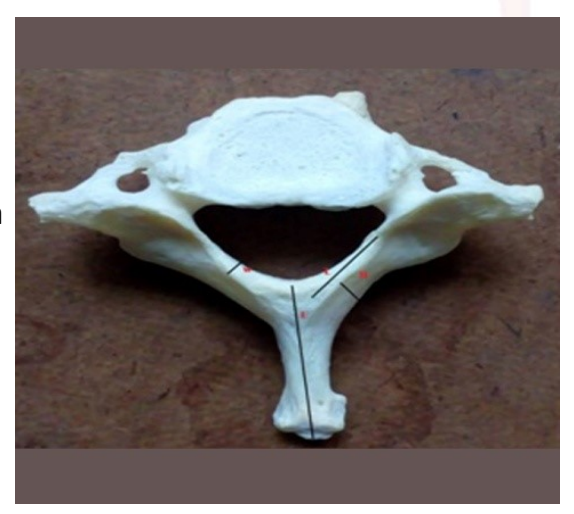

Fig. 3:

Dimension of Body Height.

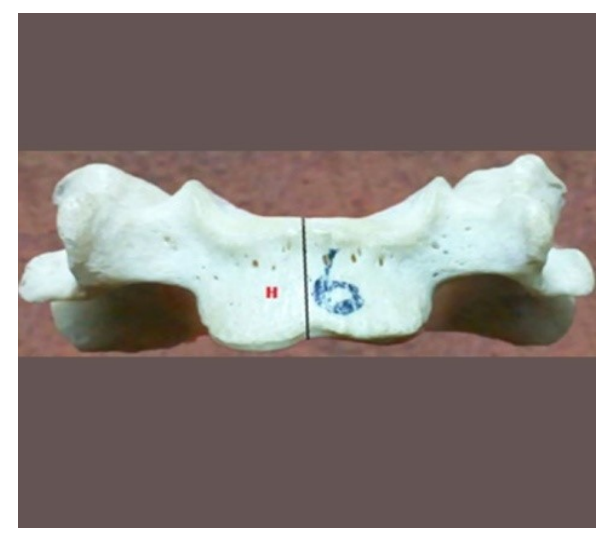

AP- Anterior Posterior Length, L - Length,

T- Transverse Length, B- Breadth, H- Height, W- Width

Table 1: Dimensions of Vertebral bodies.

\begin{tabular}{|c|c|c|c|c|c|c|}
\hline \multirow{2}{*}{ Vertebrae } & \multicolumn{2}{|c|}{ Transverse Length } & \multicolumn{2}{|c|}{ AP Length } & \multicolumn{2}{|c|}{ Height } \\
\cline { 2 - 7 } & Mean & SD & Mean & SD & Mean & SD \\
\hline C3 & 18.17 & 1.193 & 11.25 & 1.138 & 10.92 & 0.793 \\
\hline C4 & 20.5 & 1.08 & 13.2 & 1.989 & 10.3 & 0.675 \\
\hline C5 & 21.36 & 0.924 & 14.27 & 1.191 & 11.18 & 1.471 \\
\hline C6 & 25.08 & 2.61 & 15.17 & 1.586 & 12 & 1.348 \\
\hline C7 & 22.73 & 1.123 & 13.47 & 0.915 & 12.33 & 0.816 \\
\hline
\end{tabular}

Table 2: Dimensions of Pedicle.

\begin{tabular}{|c|c|c|c|c|c|c|}
\hline \multirow{2}{*}{ Vertebrae } & \multicolumn{2}{|c|}{ Length } & \multicolumn{2}{c|}{ Height } & \multicolumn{2}{c|}{ Width } \\
\cline { 2 - 7 } & Mean & SD & Mean & SD & Mean & SD \\
\hline C3 & 6.83 & 1.03 & 4.67 & 0.778 & 4.33 & 0.492 \\
\hline C4 & 5.8 & 0.632 & 4.9 & 0.876 & 4.3 & 0.823 \\
\hline C5 & 5.27 & 1.009 & 4.55 & 0.688 & 5 & 0.755 \\
\hline C6 & 4.83 & 1.528 & 6.08 & 1.165 & 6.42 & 1.379 \\
\hline C7 & 5.47 & 1.246 & 6.93 & 0.799 & 6.13 & 0.834 \\
\hline
\end{tabular}

Table 3: Dimensions of Laminae.

\begin{tabular}{|c|c|c|c|c|c|c|}
\hline \multirow{2}{*}{ Vertebrae } & \multicolumn{2}{|c|}{ Height } & \multicolumn{2}{c|}{ Length } & \multicolumn{2}{c|}{ Width } \\
\cline { 2 - 7 } & Mean & SD & Mean & SD & Mean & SD \\
\hline C3 & 9.5 & 1 & 15 & 1.206 & 3.75 & 0.622 \\
\hline C4 & 10.9 & 0.738 & 14.5 & 1.354 & 3 & 0.661 \\
\hline C5 & 12.18 & 1.328 & 14.36 & 1.69 & 2.36 & 0.505 \\
\hline C6 & 13.83 & 2.125 & 13.83 & 1.115 & 3.25 & 0.861 \\
\hline C7 & 11.8 & 1.014 & 13.07 & 1.668 & 3.4 & 0.507 \\
\hline
\end{tabular}

Table 4: Dimensions of Foramen Transversorium \& Spinous Process.

\begin{tabular}{|c|c|c|c|c|c|c|c|c|c|c|}
\hline \multirow{3}{*}{ 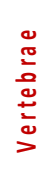 } & \multicolumn{4}{|c|}{ AP Diameter } & \multicolumn{4}{|c|}{ Transverse Diameter } & \multicolumn{2}{|c|}{$\begin{array}{l}\text { Length of } \\
\text { Spinous }\end{array}$} \\
\hline & \multicolumn{2}{|c|}{ Mean } & \multicolumn{2}{|c|}{ SD } & \multicolumn{2}{|c|}{ Mean } & \multicolumn{2}{|c|}{ SD } & \multirow{2}{*}{ Mean } & \multirow{2}{*}{ SD } \\
\hline & RT & LT & RT & LT & RT & LT & RT & LT & & \\
\hline C3 & 5.42 & 5.75 & 0.669 & 1.138 & 6.75 & 6.58 & 0.622 & 0.996 & 14.33 & 1.969 \\
\hline C4 & 5.7 & 5 & 0.949 & 0.471 & 7 & 6.4 & 0.667 & 1.35 & 17.4 & 2.366 \\
\hline C5 & 5.27 & 5.45 & 1.191 & 0.82 & 6.73 & 6.18 & 0.786 & 7.57 & 17.91 & 2.427 \\
\hline C6 & 5 & 5.83 & 2.629 & 1.337 & 5.33 & 6.92 & 2.708 & 1.78 & 25.92 & 4.379 \\
\hline C7 & 5.67 & 5.2 & 0.617 & 0.941 & 7.07 & 7.47 & 1.28 & 1.407 & 26.73 & 2.12 \\
\hline
\end{tabular}


Table 5: Comparison of body dimensions with previous studies.

\begin{tabular}{|c|c|c|c|c|c|c|}
\hline \multirow{2}{*}{ Vertebrae } & \multicolumn{2}{|c|}{ Bazaldua cruz et al [10] } & \multicolumn{2}{|c|}{$\begin{array}{r}\text { Gajendran prabavathy et al } \\
{[11]}\end{array}$} & \multicolumn{2}{c|}{ Present study } \\
\cline { 2 - 7 } & T & AP & T & AP & T & AP \\
\hline C3 & $19.17 \pm 3.04$ & $14.38 \pm 2.63$ & $22.8 \pm 0.101$ & $13.18 \pm 0.33$ & $18.17 \pm 1.193$ & $11.25 \pm 1.138$ \\
\hline C4 & $20.75 \pm 1.86$ & $16.36 \pm 0.99$ & $23.54 \pm 0.26$ & $14.4 \pm 0.29$ & $20.50 \pm 1.08$ & $13.2 \pm 1.98$ \\
\hline C5 & $20.88 \pm 3.73$ & $17.45 \pm 1.29$ & $26.46 \pm 0.51$ & $15.4 \pm 0.29$ & $21.36 \pm 0.924$ & $14.27 \pm 1.49$ \\
\hline C6 & $22.17 \pm 2.17$ & $17.49 \pm 1.48$ & $25.42 \pm 0.38$ & $16.34 \pm 0.53$ & $25.08 \pm 2.61$ & $15.17 \pm 1.586$ \\
\hline C7 & $23.44 \pm 3.48$ & $17.42 \pm 1.33$ & $26.12 \pm 3.76$ & $16.12 \pm 0.57$ & $22.73 \pm 1.123$ & $13.47 \pm 0.955$ \\
\hline
\end{tabular}

Table 6: Comparison of pedicle Dimensions.

\begin{tabular}{|c|c|c|c|c|c|c|c|c|c|}
\hline \multirow{2}{*}{ 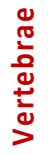 } & \multicolumn{3}{|c|}{ Bazaldua cruz et al [10] } & \multicolumn{3}{|c|}{ Gajendran prabavathy et al [11] } & \multicolumn{3}{|c|}{ Present Study } \\
\hline & Length & Width & H & Length & Width & H & Length & Width & H \\
\hline C3 & $5.9 \pm 0.24$ & $2.8 \pm 0.10$ & NA & $5.27 \pm 1.37$ & $5.14 \pm 2.2$ & NA & $6.85 \pm 1.03$ & $4.33 \pm 0.49$ & $4.67 \pm 0.778$ \\
\hline C4 & $6.14 \pm 1.21$ & - & NA & $23.54 \pm 0.26$ & $4.47 \pm 1.08$ & NA & $5.8 \pm 0.63$ & $4.3 \pm 0.823$ & $4.90 \pm 0.876$ \\
\hline C5 & $4.46 \pm 0.70$ & - & NA & $26.46 \pm 0.51$ & $4.55 \pm 0.98$ & NA & $5.27 \pm 1.0$ & $5 \pm 0.773$ & $4.55 \pm 0.688$ \\
\hline C6 & $5.36 \pm 0.39$ & - & NA & $25.42 \pm 0.38$ & $4.84 \pm 1.17$ & NA & $4.83 \pm 1.528$ & $6.42 \pm 0.379$ & $6.08 \pm 1.165$ \\
\hline $\mathrm{C7}$ & $5.44 \pm 0.5$ & $4.96 \pm 0.37$ & NA & $21.20 \pm 0.5$ & $4.20 \pm 0.54$ & NA & $5.47 \pm 1.246$ & $6.13 \pm 0.834$ & $6.95 \pm 0.799$ \\
\hline
\end{tabular}

Foramen transversorium: $\mathrm{AP}$ and transverse length of Foramen transversorium of both sides was measured; AP length of FT on RT side was maximum at $\mathrm{C} 4$ but on left side it was maximum at C6; Transverse length of FT on RT side was maximum at $\mathrm{C} 7$, it was also maximum at C7 on left side (Table 4).

\section{DISCUSSION}

The Anatomical details and dimensions of cervical vertebrae are very important for cervical Spine instrumentation like Trans pedicle screwing [3]. Many Authors have explained about various dimensions of cervical vertebrae by studying CT scan, Direct measurements in bone specimens (Abuzayed et al [3], pankaj \& Nepal et al [4], Sandeep saluja et al [5], Chen chun et al [6],Partha sarathy Banerjee et al [7]). They have spent their valuable time in these analyses. But there are variations in the dimensions due to life style changes, genetic makeup, geographic factors and also varies in the races (yusof et al [8]). Our present study will provide knowledge about the dimensions of sub axial vertebrae in south Indian population. In our present study transverse length of body was minimum at $\mathrm{C} 3$ maximum at $\mathrm{C} 6$ (Table 1).Body height was minimum at $\mathrm{C} 4$, maximum at C7(Table 1). These body dimensions were in concurrence with Ephrahim et al [9] study. In
Bazaldua C.J.J et al [10] study transverse length of body increases gradually from $\mathrm{C} 3$ to $\mathrm{C} 7$. According to Gajendran prabavathy et al [11] body height was minimum at $\mathrm{C} 3$, maximum at C7. The body height dimensions were varied from Gajendren prabavathy et al [11] study. Variations in the dimensions of body are important for many surgical procedures like Decompression Surgeries to remove disc or to remove bony spur which compresses spinal cord. It is also useful during corpectomy procedure where removal of entire body is done to gain access to disc material, also for transcorporeal micro decompression (TCMD). TCMD procedure accesses the cervical spine from front of Neck. The morphometry of cervical vertebral pedicles was studied by Kayalioglu et al. [12] In that study greatest pedicle length was at C3.

In our present study pedicle length was maximum at C3 Minimum at C6 level .But pedicle width gradually increases from C3 to C6 level. Pedicle height was also gradually increases from C3 to C6 level. These dimensions were varied from previous studies $[11,12]$. These may be due to geographical factors, food habits, and environmental conditions.

The pedicle dimensions will be useful for selecting the screw size in transpedicular screwing techniques [Abumi et al [13], Bozbuga et al [14], Ludwig et al [18]. 
The morphometry of cervical vertebra which was studied by Gajendran Prabavathy et al [11] where maximum pedicle length was noted at C3, Minimum pedicle length was noted at C5, This was in variance with our present study.

The Lamina dimensions are very important for laminotomy (where making hole in lamina to create more space for spinal cord), laminectomy where removal part or all of lamina to reduce pressure on spinal cord \& also in laminoplasty procedure $[15,16,19,20]$. These are all decompression procedures frequently used for the treatment of cervical spondylosis, mylopathy, tumors of spinal medulla (wang et al [16]). In our present study the maximum lamina length was at $\mathrm{C6}$, was minimum at C3; the maximum lamina height was at $\mathrm{C} 3$, minimum lamina height was at C7.

According to Bazaldua et al [10] the length of spinous process was minimum at $\mathrm{C} 3$ and maximum at C7.In our present study spinous process length was minimum at $\mathrm{C} 3$, it gradually increases from C3 to C7 was maximum at C7. Spinous process dimensions are important for decompression procedures from behind.

According to Richa gupta et al [17] foramen transversorium AP length was minimum at C3, maximum at C6.Transverse length was minimum at $\mathrm{C} 3$, maximum at $\mathrm{C} 5$. In our present study AP length was minimum at $\mathrm{C} 6$, maximum at $\mathrm{C} 4$ and transverse length was minimum at C6, maximum at C7.These dimensions were varied from previous study.

The dimensions of foramen Transversorium are very important for foraminotomy procedure where Intervertebral disc or a bony spur is pressing on a Nerve as it exits through the foramen, a foraminotomy may be done. This is making the opening of the foramen larger, so the Nerve can exist without being compressed.

\section{CONCLUSION}

The dimensions of body and spinous process were increased from C3 to C6. But laminae length decrease gradually from C3 to C7.Pedicle length was gradually decreases from C3 to C6. But pedicle width and height gradually increases from c3 to $c 6$. These results were varied with previous studies. This may be due to nutrition factors and environmental conditions. These results will be helpful in spinal fixation surgeries, decompression surgeries and also useful for orthopaedicians to diagnose and interpret radiological images.

\section{Conflicts of Interests: None}

\section{REFERENCES}

[1]. Grays anatomy., $39^{\text {th }}$ Edition.,Churchill Livingstone 1989 .

[2]. Dr.Yuranga Weerakkody and Dr.Roberto schbert et al Three column concept of spinal fractures, Radiopaedia.org

[3]. Abuzayed B.,Tutunculer B.,kucukyuruk B.,Tuzgen S.(2010)Anatomic basis of anterior and posterior instrumentation of the spine :morphometric study.surg.Radiol.Anat. 2010;32:75-85.

[4]. Pankaj R Nepal , Anthropometric study of cervical spine in Adult Nepalese, The journal of spinal surgery , April - June 2017 4(2): 55-59

[5]. Sandeep Saluja, Morphometric Analysis of Subaxial Cervical Vertebrae and Its Surgical Implications, Journal of Clinical and Diagnostic Research. 2015 Nov;9(11):AC01-AC04.

[6]. Chen Chun, CT Morphometric Analysis to Determine the Anatomical Basis for the Use of Transpedicular Screws during Reconstruction and Fixations of Anterior Cervical Vertebrae, December 2013;8(12).

[7]. ParthaSarathi Banerjee, Morphometric analysis of the cervical spine of Indian population by using computerized tomography, J Med Allied Sci. 2012;2(2):66-76.

[8]. Yusof MI, Ming LK, Abdullah MS, Yusof MI. Computeriraphic measurement of the cervical pedicles diameter in a Malaysian populationand the feasibility for transpedicular fixation.Spine 2006;E221-E224

[9]. Ephraim Vikram Rao, Morphometric analysis of typical cervical vertebrae and their clinical implications: a cross sectional study, International Journal of Anatomy and Research, Int J Anat Res 2016;4(4):2988-92. ISSN 2321-4287

[10]. Bazaldua C .J.J.,Gonzalez Lario L.A.,Gomez S.A. Morphometric study of cervical vertebrae C3-C7 in a population from Northeastern Mexico.Int.J.Morphol. 2011;29:325-330.

[11]. Gajendran prabavathy., Morphometric study of cervical vertebrae C3-C7 in south Indian populationA clinic-anatomical approach., Italian journal of anatomy and physiology. 2017;122(1):49-57.

[12]. Gulgun Kayalioglu., Morphometry of the Cervical Vertebral Pe dicles as a Guide for Transpedicular Screw Fixation., Neurol Med Chir(Tokyo) 47,March,2007.

[13]. Abumi K,Shono Y,Kotani Y,Kaneda K;Indirect posterior reduction and fusion of the Traumatic herniated disc by using a cervical pedicle screw system.J Neurosurg 92:30-37. 
[14]. Bozbuga, Mustafa MD., Morphometric Evaluation of Subaxial Cervical Vertebrae for Surgical Application of Transpedicular Screw Fixation, Spine. 1 September 2004;29(17):1876-1880.

[15]. Hosono, Noboru MD., Neck and Shoulder Pain After Laminoplasty: A Noticeable Complication., Spine: 1 September 1996;21(17):1969-1973.

[16]. Wang JM,Roh KJ,Kim DJ.,Kim DW.A New Method of stabilizing the elevated laminae in open door-door laminoplasty using anchor system.J Bone Joint surg.1998;80(6):1005-8.

[17]. Dr. Richa Gupta, Variations in morphometry of foramina transversaria and vertebral artery in subaxial cervical region and its Surgical implications, International J. of Healthcare and Biomedical Research 2014;3(1):47-54.
[18]. Ludwig, Steven C. MD., Placement of Pedicle Screws in the Human Cadaveric Cervical Spine: Comparative Accuracy of Three Techniques, Spine: 1 July 2000;25(13):1655-1667

[19]. Joshua J. Chern, M.D., Ph.D., Computed tomography morphometric analysis for axial and subaxial translaminar screw placement in the pediatric cervical spine. Pediatrics. 2009 Feb;3(2):121-8.

[20]. Lance K. Mitsunaga, Laminoplasty Techniques for the Treatment of Multilevel Cervical Stenosis., Advances in Orthopedics Volume 2012;Article ID 307916, 15 pages

\author{
How to cite this article: \\ V.Ananthi, S.Umarani, V.Muniappan. VARIATIONS IN THE \\ DIMENSIONS OF SUB AXIAL VERTEBRAE AND ITS CLINICAL \\ SIGNIFICANCE. Int J Anat Res 2017;5(4.3):4740-4745. DOI: \\ 10.16965/ijar.2017.461
}

